\title{
Dynamics of competitive forms of social partnership and their management in modern Russian society
}

\author{
Valery Levchenko* \\ Perm National Research Polytechnic University, Komsomolsky Avenue,29,Perm,614990, Russia
}

\begin{abstract}
The author proposes to consider the process of optimization of social partnership management with regard to its competitive forms, relying on fairly representative and fairly numerous results of specific sociological studies carried out over more than three decades. The structure of competitive forms of social partnership and its changes over several decades in modern Russian society are analyzed.The main determinants defining the development of competitive forms of social partnership are presented. The main consequences (effects) of various competitive forms of social partnership for the productivity of activities, interpersonal relations and personal development are revealed.In particular, it is found that the strongest positive effect on practically all aspects of human life is provided by cooperative forms of social partnership and passive forms of competitiveness and individualism have the greatest negative effect. It is proposed to use the revealed patterns of competitive forms of social partnership in order to optimize management both in the system of social partnership and social interaction in general.
\end{abstract}

\section{Introduction}

Social partnership with regard to socio-economic analysis can be presented as a kind of manifestation of subject-subject relations, which can take various forms $[1 ; 2]$.Accounting and optimal use of various forms of social partnership play a fairly important role in the management system in modern society.One of the most universal options for the analysis of the forms of social partnership is their consideration from the standpoint of competition $[3 ; 4 ; 5]$.

The author propose to consider competitiveness as a category that has particular types of its manifestation, as a special form of «co-activity» of people, carried out through the implementation of mechanisms for comparison, validation and regulation by the subject of activity in the process of exchange with the environment, serving as the basis for the changes in his activity and the quality of interconnection with other subjects and which is a consequence of two ambivalent properties typical of a social subject: the property, expressed in the desire to distinguish oneself and the property, manifested in the tendency to interact $[3 ; 6 ; 7]$. At the same time, it is proposed to single out four main competitive forms of social partnership as particular manifestations of competitiveness on such grounds as the direction and intensity of interaction: competitiveness, altruism, cooperation, individualism. The competitive form of social partnership is an expression of one of two tendencies inherent in a subject - the demonstration of the private interest of a subject (when a subject pursues his private, individual goals, usually against the interests of other subjects) in the process of comparison, evaluation and regulation of his activities.The opposite competitive form of social partnership can be considered as altruism and it is also a one-sided manifestation, but already of a different tendency inherent in a subject of social interaction (a tendency towards integration, subordination to a group, often against oneself and one's interests). Theoretically, the optimal competitive form of social partnership is cooperation, which is a mechanism for mutual stimulation of the activity of subjects in the process of comparison, evaluation and regulation of their activities, when the maximum possible (but not necessarily the same) simultaneous realization of two opposite tendencies inherent in a subject in relations of social partnership occurs: self-realization of a subject and the realization of common interests.

In other words, subjects achieve their goals only when other partners also achieve them, when maximization of mutual benefits takes place and not their equality.Another competitive form of social partnership is individualism, when a partner achieves his goals without any connection with the achievements of others [3;8]. There is also an intermediate competitive form of social partnership, when the subjects of competitive relations are usually inferior in something to each other, but at the same time they ensure the partial realization of their goals and interests.

\section{Results and discussion}

The research on the basis of the Department and Laboratory of Sociology of Perm National Research Polytechnic University which is conducted regularly from 1979 to 2017 covered more than 13,000 people. The competitive forms of social partnership in various spheres of life (socio-political, socio-cultural, leisure,

\footnotetext{
Corresponding author: levv66@mail.ru
} 
etc.) were studied, but the main attention was paid to their peculiarities in professional sphere.

The analysis of changes in the competitive forms of social partnership over the past three decades has revealed the following patterns. Firstly, almost all types of competitive forms of social partnership have been constantly determined for more than three decades. If we summarize all the data for the specified period of time, then the distribution of competitive forms of social partnership can be represented as follows (Figure 1).

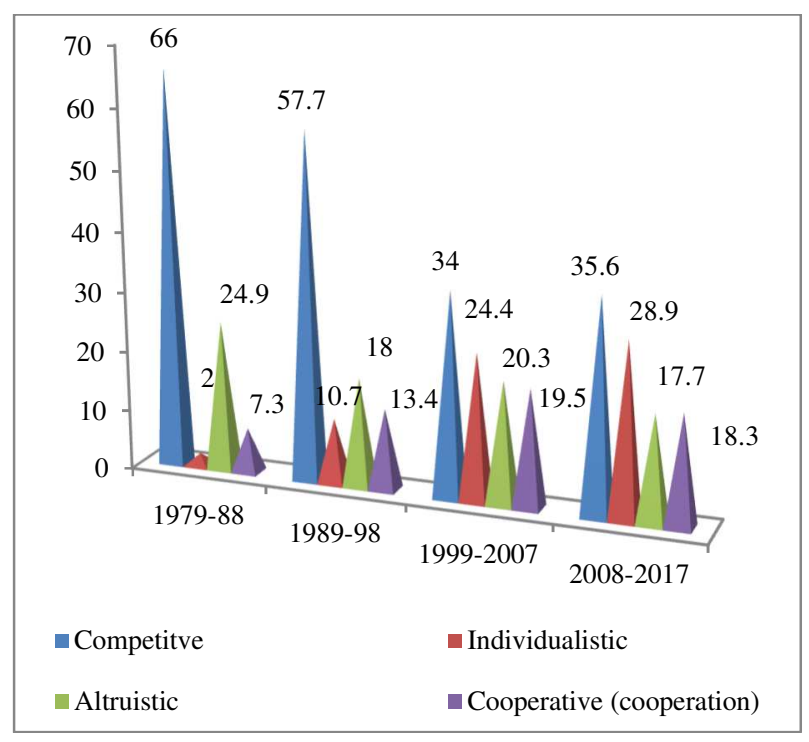

Figure 1.Dynamics of competitive forms of social partnership in modern Russian society from 1979 to $2017, \%$

Secondly, if we analyze specific changes in the competitive forms of social partnership for a given period, then it is necessary to note the predominance of competitive forms throughout the entire time period with a gradual decrease in their level (first of all, passive forms of competition), a certain decrease in passive (reactive) forms of altruism, a gradual increase in active cooperation and a confidently significant increase in the number of respondents with individualistic positions.

We also should pay attention to one more tendency to change the competitive forms of social partnership a significant consistent increase in active forms of competition and, at the same time, a methodical reduction in passive forms of social partnership (Figure 2).

It is possible to note that the results of our research generally coincide with the limited data on the distribution of competitive forms of social partnership obtained by G.E. Belitskaya [9] and J. Reikovski [10, p. 29-32], and reflect the main trends of their changes in modern society. In particular, J. Reikowski notes that "in modern society: Polish, Russian and other former countries of "socialist direction", there is a tendency towards the complete destruction of the collectivist orientation and the progress of individualization" $[10, p$. 29-32]. G.E. Belitskaya revealed that in modern Russian conditions the predominant type of personal consciousness of social problems is competitiveness ( $\ll \mathrm{I}$ am the subject»- «society is an object»), which is an «active, empirical, optimal type» with a predominance of individual values [9, p. 60-62]), clarifying and specifying the outlined changes. Thus, the turning point (that is, when the most significant changes in the development of competitive forms of social partnership took place) can be considered as the time from 1991 to 1998. Since 1999, a certain stabilization in the state of competitive forms of social partnership begins.

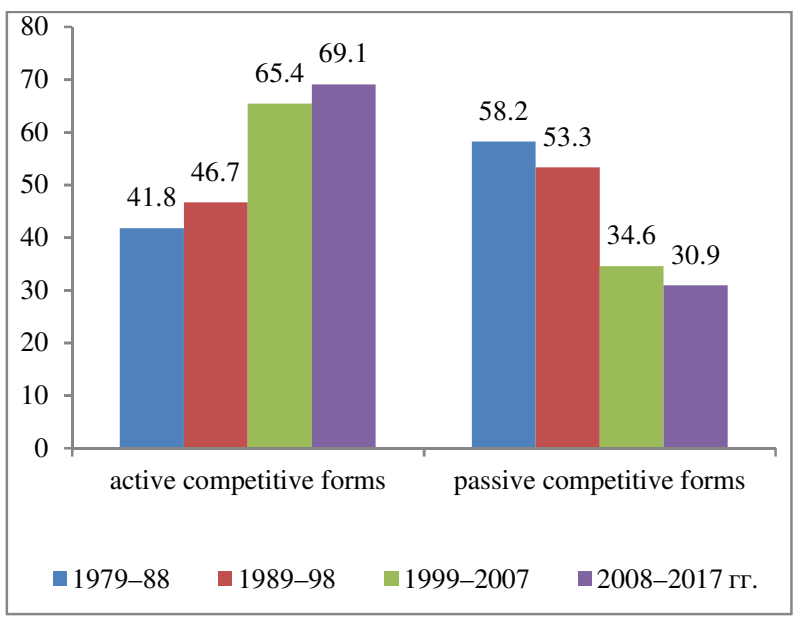

Figure 2.Distribution of active and passive competitive forms of social partnership from 1979 to 2017 , \%

It is precisely these periods in the development of Russian society that are considered to be as follows: transitional (crisis) - the beginning and mid-1990s, and the beginning of stabilization (the beginning of the XXI century). Thus, competitive forms of social partnership may be one of the most accurate and unified indicators of social development of society at different levels.

Thus, the proposed approach to the consideration of this phenomenon can be used to optimize the process of management (regulation) of social interaction at all levels (from interpersonal to interstate) and in all areas of joint activity (taking into account the characteristics of each of the competitive forms of social partnership allows more accurate and a differentiated approach to the problem of the improvement of the organization of joint activities).The analysis of the development of competitive forms of social partnership in various social groups also allowed concluding that competitive forms of social partnership can be considered as a significant and sufficiently sensitive to the influence of various factors (from factors of the macroenvironment to intrapersonal) of differentiating criterion of intragroup structuring.

The results of these studies indicate that competitive forms of social partnership are not just one of the indicators of the formation of joint relations, but are one of the most accurate and sensitive indicators of this social (and socio-psychological) phenomenon. It was found that competitive forms of social partnership are one of the leading determinants of social (group) structuring. Moreover, competitive forms of social partnership are at the same time one of the main sources 
of the development of joint relations in society (due to the internal contradictions inherent in them), and one of the most accurate and reliable indicators of the level of development of joint relations.

Thus, at the initial stage of the development of joint relations (the stage of scattered, unformed social relations, the stage of diffuse group), such a competitive form of social partnership as competitiveness is most often spread. Such a competitive form of social partnership as altruism usually prevails at the intermediate, marginal level of the formation of joint relations (a stage of association). At the highest stage of development of social relations (in a highly cohesive social group, collective, team), such a competitive form of social partnership as cooperation often prevails. First of all, a higher level of development of social relations is determined by a higher integrity of functioning in subjects of such a competitive form of social partnership as cooperation. Since this very form of social partnership (cooperation) has more complete (holistic) involvement of the essential properties of the subject of competition - simultaneous maximum involvement in social partnership relations of not one, but both tendencies typical of the subject of cooperation.

Thus, the internal contradiction of competitive forms of social partnership, which has constant asymmetry, acts as one of the main sources of selfdevelopment and joint relationships. Cooperation, a the most progressive competitive form of social partnership largely determines the development of the most progressive form of social relations communitarianism, « real collectivity », a real team and the highest stage of development of social partnership.

Such objective and subjective factors as the state of the wide social environment at the level of society as a whole, the form of ownership of the organization, social and professional status (content of work, profession), level of education, involvement in power relations (participation in management, political activity, etc.), value orientations of subjects, personality traits etc. have the most significant effect on the formation of competitive forms of social partnership [3].

The performed analysis of the effect of various factors made it possible to clarify the system of the main determinants of each competitive forms of social partnership to a certain extent. In particular, competitiveness is most intensively formed and developed among employees of state-owned organizations (in comparison with organizations of other forms of ownership), among women (in comparison with men), among young people (in comparison with older age groups), among employees with secondary education (in comparison with workers with higher education), among respondents with a predominance of such life values as "career" and "personal business qualities", among respondents with radical forms of political activity and such personality traits as high "irritability", high "sociability", a high level of "self possession", lack of "shyness", with a high level of "need for achievement".
The development of competitiveness is negatively affected by joint-stock ownership, professional membership in a group of specialists or managers, predominance of orientation towards work or profession, traditional legitimate forms of political activity, and such personality traits as "masculinity".

The formation of individualism is positively influenced by the state form of ownership of an enterprise, an uncertain position of participation in management, belonging to a group of women workers with a secondary education, paternalism, indifference to politics and low level of "spontaneous aggressiveness". Membership in a professional group of specialists or leaders, radical forms of political activity, a high level of "need for achievement" negatively affect the development of individualism.

Joint-stock ownership of an enterprise, participation in management, belonging to a group of older men with secondary general or higher education, employees or managers, predominance of orientations towards "work, profession" or "career", legitimate forms of political activity, pronounced "masculinity", a low level of "irritability" and "irritability" have a positive effect for altruism. The state form of ownership of an enterprise, young age (up to 30 years), belonging to a professional group of workers, political passivity and some personality traits (high "reactive aggressiveness", "irritability", "sociability") negatively affect the formation of altruism.

The development of cooperation is positively influenced by joint-stock ownership, participation in management, belonging to a social group of men, specialists or managers with higher education, orientation towards "work, profession", "culture, education", "personal business qualities", relying on "their own forces (not state assistance)", legitimate forms of political activity, a high level of personality traits such as "self-possession", "masculinity", "need to achieve", a low level of "irritability".

The following factors as state ownership, membership in a professional group of employees, radical forms of political activity, a high level of "reactive aggressiveness", "sociability" have a negative impact on the formation of cooperation.

More important patterns were identified during thestudy of the influence of competitive forms of social partnership on performance, interpersonal relationships and certain aspects of personality development. In addition, the scheme used for the analysis of competitive forms of social partnership made it possible not only to bring some clarity on one of the most confusing problems of competitivenessi.e. the issue of the consequences of the effect of competitive forms, but also to clarify significantly the differentiating effect of each of the twelve competitive forms of social partnership in various spheres of life such as the productivity of activity, joint group existence and personal development.

It is found that such a form of competition as active cooperation is determined by the strongest optimizing and unambiguous positive influence on all aspects of the life of a subject such as the effectiveness of his 
activities, interpersonal relations and the state of a personality. Other competitive forms of social partnership are not only inferior to cooperation in terms of the strength of their impact, but also do not have such unambiguous consequences in various spheres of life. Thus, competitive forms of social partnership have a rather strong, although second largest optimizing effect on objective performance indicators after cooperation.

At the same time, the subjective assessment of these consequences, as well as the impact on the sociopsychological climate of the group and personal development, is lower than similar indicators in subjects with a mindset for cooperation and altruism. Altruistic forms of social partnership, being inferior to cooperation and competitive forms of social partnership in terms of their impact on objective performance indicators, nevertheless constantly rank second place in terms of their beneficial effect on the sociopsychological climate, interpersonal relations and personality development.

That is, the subjects with an orientation towards altruistic forms of social partnership are characterized by a more optimistic subjective position in relation to their activities and social environment. The influence of such a competitive form of social partnership as individualism on the productivity of activities and the socio-psychological state of a group is relatively weak and is inferior to the strength of the influence of other forms of social partnership. We can also pay attention to some increase in the negative impact of the individualistic form of social partnership on the indicators of personal adaptation.

There is also a stronger positive effect on the performance, interpersonal relations and personality development of active competitive forms of social partnership compared to the influence of similar passive competitive forms of social partnership. Thus, it can be noted that the most controversial competitive form of social partnership in terms of its consequences is passive altruism and predominantly negative effects are typical of such passive competitive forms of social partnership as competitiveness and individualism.

At the same time, the passive competitive form of social partnership has a more negative effect on the socio-psychological state of a group and the passive individualistic form of social partnership - on the wellbeing of an individual [8]. The discovered differentiating effect of various competitive forms of social partnership can be explained by their inherent essential characteristics: the completeness of the implementation of essential properties of a subject of competitive forms of social partnership and the level of their intensity. In turn, the revealed patterns of functioning of competitive forms of social partnership can (and should) be used to optimize the management of social and interpersonal interaction.

\section{Conclusion}

It turns out that competitive forms of social partnership are one of the essential differentiating features of intragroup structuring and social development, which, on the one hand, is sensitive to the influence of macro- and microconditions. On the other hand, competitive forms of social partnership have a strong and fairly unambiguous effect on the main spheres of human activity (performance, social relations and personality development). They can reasonably be considered as one of the indicative and universal factors of the social and socio-psychological development of a particular subject of interaction and one of the main sources of activity of subjects of joint activity.

\section{References}

1. N.A. Kolesnikova, Nesterov Yu.A. Socioeconomic and humanitarian journal of Krasnoyarsk State Agrarian University, 1(7), (2018)

2. D.G. Pruitt Negotiation behavior(New York: Academic Press,2013)

3. V.V. Levchenko, Bulletin of the Peoples' Friendship University of Russia, Psychology and Pedagogy, 2, 32-36, (2010)

4. R. Axelrod, The evolution of cooperation, New York, Perseus Books Group, (2006)

5. A.G. Shmelev, Productive Competition. Experience of constructing a unifying concept, Institute «Open Society», 55, (Moscow: Magister, 1997)

6. B.D. Bonta, Psychological Bulletin, 121(2), 299320, (1997)

7. M. Deutsch, The Handbook of Conflict Resolution: Theory and practice, 3rd Edition (San Francisco: Jossey-Bass, 2014)

8. V.V. Levchenko, O.V. Yuryeva, E.N. Rastorgueva, J.S. Neverova, L.Y. Talipova, Espacios, 40(25), (2019)

9. G.E. Belitskaya, Psychological journal, 15(4), 54-63, (1994)

10. J. Reikovski, Journal of Psychology, 14(5), 2334, (1993) 